\title{
The Interplay between Informal and Formal Bylaws in Supporting Sustainable Crop Intensification in the Uganda Potato Production System
}

\author{
Makuma-Massa Henry ${ }^{1}$, Paul Kibwika ${ }^{1} \&$ Paul Nampala ${ }^{2}$ \\ ${ }^{1}$ Department of Extension and Innovation Studies, College of Agricultural and Environmental Sciences, \\ Makerere University, P. O. Box 7062, Kampala, Uganda \\ ${ }^{2}$ Uganda Christian University, P. O. Box 4. Mukono, Uganda \\ Correspondence: Makuma-Massa Henry, Department of Extension and Innovation Studies, College of \\ Agricultural and Environmental Sciences, Makerere University, P. O. Box 7062, Kampala, Uganda. E-mail: \\ henrimassa@yahoo.com
}

Received: January 10, 2022 Accepted: February 16, 2022 Online Published: March 5, 2022

doi:10.5539/sar.v11n2p1 URL: https://doi.org/10.5539/sar.v11n2p1

\begin{abstract}
The study assessed the interplay between informal and formal bylaws in supporting sustainable crop intensification, using a case of potato crop production in southwestern Uganda. The study used a descriptive case study design to understand and accurately describe the experiences of farmers in the potato crop subsector in the region. This involved mixed study approaches that ensured coded meaning of consistent responses to the study, and descriptive statistics facilitated sequential understanding of findings and how each related to one another in respective themes. The numerical scores enriched the findings by authenticating the qualitative outcomes of the study to minimize bias. The study used review of documents and literature; six Focus Group Discussions; and 22 Key Informant Interviews to gather diverse experiences of respondents patterns of responses, the main factors or categories, and key responses under every category. The Study found that the greatest informal bylaw was eucalyptus growing (50 percent), followed by permission to graze (18 percent), and control damping (18 percent). The widely represented formal bylaws had a comparatively lesser role in supporting SCI, although with greater emphasis on quality seed (22 percent). Formal bylaws were stronger at setting clear boundaries between users and resources (18 percent), users having procedures for making own rules (11 percent), regular monitoring of resources and users (15 percent), issue sanctions (16 percent), conflict resolution (15 percent), and coordinated activities ( 3 percent) than informal bylaws. The major benefits for operating as institution were the collective strategy for the market (26 percent), which was less to guarantee sustainable livelihoods for farmers. Individual farmers were driven by desire for faster benefits (13) and preferred following own rules (12 percent). There was more emphasis on market access, regardless of the nature of produce output (35 percent), whether the market worthy or not, and less on environment sustainability. The informal and formal bylaws are separate but united for a common purpose of intensifying potato crop production. Nonetheless, even when combined, they are not strong enough to support SCI. There is a need to strength bylaws on soil and water conservation, improved and quality seed potato and environment sustainability to support SCI, which provide the basis of greater markets and sustainable livelihoods.
\end{abstract}

Keywords: Uganda, sustainable crop intensification, formal bylaws, informal bylaws, policy implementation, potato

\section{Introduction}

Globally, more than 118 million people faced hunger in 2020 than 2019 due outbreak of Covid19, which destabilized economies (Food and Agriculture Organisation, International Fund for Agriculture Development, United Nations Children Fund, World Food Programme, and World health organization, 2020). By addressing Sustainable Development Goals (SDG) 2: zero hunger, the global population gets closer to meeting higher goals (United Nations Industrial Development Organization, 2020). This study targets global efforts towards inclusive and sustainable development through applicable of bylaws to intensify potato production in spite of the scarce and diminishing value of land resources to supply adequate food requirements for the growing population 
(Otsuka and Place, 2014; Pretty, 2011).

According to the new institutionalism theory by North (1990), the evolution of institutions involves formulating group rules and norms, which direct behaviour towards the fulfilment of a specific goal. Bylaws evolve out of experiences and lessons about how to conserve soil and water, ensure seed quality, handle crop yields, and access markets. Bylaws were written (formal) or unwritten (informal) (Yami et al., 2012; Helmke and Levitsky, 2004; North, 1990; Sanginga et al., 2009).

Therefore, the operationalization of bylaws-centered policies within socially-responsive institutions is most ideal for supporting SCI. Individual farmers may follow bylaws, bylaws-driven and institutionally-evolved policies, but remain reluctant to operate within social groups, farmers' associations, or institutions to achieve SCI. The bylaws evolve as simple rules developed and agreed to by farmers' associations to strengthen their focus, effort, and actions towards achieving SCI in the production of the potato as a cash crop. Classical studies have considered individual interests as ones that influence social interests towards growth and development (Boserup, 1965). Individual farmers tend to be aware of the local bylaws or bylaw-driven institutional policies for sustainable farming, but prefer to operate outside farmers' groups or associations. The loosely coordinated collective individual responsibility towards implementations of bylaws to support SCI is most consequential and sustainable, where each farmer works for the general good of everyone else. Ostrom (1990) presented the eight design principles of effective institutions through loose and fair management of people to respond towards a set strategy, such as setting boundaries, harmonized costs and benefits, setting procedures for making rules, regular monitoring, conflict resolution, respect for rights, and coordinated activities of associations. This study explored ways for achieving SCI through the procedural application of informal and formal bylaws to support institutional policy development in farmers' association within potato production system to sustain economies and livelihoods of people in SWU.

The formulation of evidence-based policies within institutions relies on stakeholders' opinions and reports on ongoing implementation processes (Strehlenert, et al., 2015). This creates and facilitates a system of checks and balances during the implementation of the bylaws and bylaw-centered policies to support SCI. According to (Yami and Van Asten, 2017), policy-driven institutions contribute to SCI in Eastern Africa. However, exiting agriculture policies are operationalized across production sectors. Hence, they are not specific to guiding production in the potato sector, which has unique needs. They also focus on output rather than sustainability beyond production benefits like food and nutritional security, employment, reducing income inequality, stimulating investments and growth of local and international commerce (Ministry of Agriculture, Animal Industry, and Fisheries, 2013).

Thus, the influence of bylaws (informal and formal) in their formulation for the sustainability of agricultural policies is not articulated. For a long, the studies on SCI have emphasized the biophysical factors rather than institutional and policy-driven bylaws (Vanlauwe et al., 2014; Schut et al., 2016). This study argues that policies applicable in supporting SCI are those that are adapted to existing bylaws and operationalized within institutions for them to be effective and sustainable at intensifying potato crop production. SCI is premised on four key aspects: 1) necessity to increase production, 2) higher yields on smallholder farmland, 3) minimise environmental costs and maximise sustainability, and 4) appropriate agricultural techniques (Garnett et al., 2013). The rising demand of potato crop in urban areas has led to the economic boom in rural potato growing areas (National Agriculture Advisory Services, 2020). SCI strategy is, thus, the answer for the population to cope with demand. However, there is limited data about the role of bylaws in supporting SCI in potato production. While institutions provide a viable framework for managing common-pool resources and support intensification of potato crop production feasible, there is little knowledge about how their regulatory frameworks are developed and implemented to intensify potato production, ensure the efficacy of such implementations, and demonstrate the influence of bylaws in formulating the operationalized policies within institutions. It is also speculative to suggest that institutional weaknesses influence individuals to operate outside farmers' groups. This study contributes effective ways through which bylaws strengthen policies and institutions to support SCI, beyond the current focus on biophysical interventions, without which sustainable livelihoods of people can remain a dream. The study assesses the interplay between informal and formal bylaws in supporting potato crop intensification in SWU, by assessing the relationship between informal and formal bylaws, individual farmers and institutional framework for implementing bylaws, and the overall effect they have on SCI.

\section{Conceptual and Analytical Framework}

The conceptual framework is developed from analysis of the theoretical perspectives of the study, especially Boserup (1965); Ostrom (2009); Cox, Arnold, Villamayor-Tomas (2010); and Xie, Huang, Chen, Zhang, and Wu 
(2019), which positions individual merit and socioeconomic perspective-based informal and formal bylaws, functioning within the institutional framework and individual farmers' behaviours for supporting SCI in potato cropping system in SWU. According to Ostrom (1990), effective group management based agreeable mode of operation within networks of farmers' entities, improved response towards a group goal. Boserup (1965:14) observed that the growing population was inevitable and irreversible, which implied the need to focus on improving soil fertility to increase production and ensure food security, through practices like the application of animal manure, short fallow rotations, terracing, and intensive farming in areas with dense population. However, Boserup's work has been criticized for simplifying the dynamics of agricultural systems and considering population pressure as the sole driver of change, whilst ignoring the role of local policies, markets, and institutions they functioned under, such as governments and environmental conditions (Djurfeldt et al., 2005; Brookfield, 2001).

According to The new intuitionalism theory (NIT), the formal and informal laws are key to institutional change. An adaptive institutional framework readily adapts to changing circumstances and such frameworks encouraged decentralized decision making and enable society to maximize opportunities for problem-solving during the change process (North, 1994:367; 1990:81). The change is guided by humanly-devised informal and formal rules or constraints, which influenced interaction towards a collective need or goal (North, 1990:3,4). This study details the role of institutionalism versus individualism. To varying extents, potato farmers tended to be either institutional or individualistic in their approach to potato production in SWU. Thus, the study assesses the interplay between informal and formal bylaws and their effect on individual and institutional frameworks for developing and implementing bylaws to intensify potato crop production in SWU. In this study, achieving SCI (DV) is dependent on the interplay between informal and formal bylaws (IV), and operationalized as policies in institutions (farmers' associations) and individual behaviours (MV) to support SCI (Figure 1).

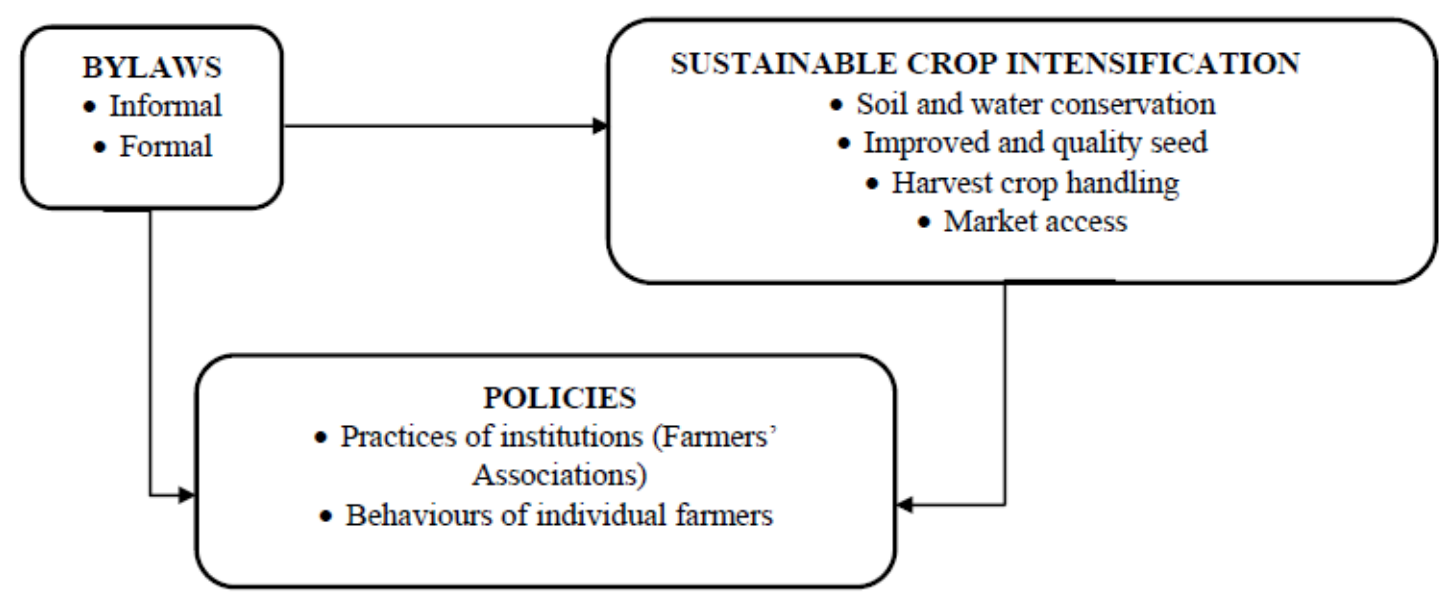

Figure 1. Relationship between study variables

\section{Methodology}

\subsection{Area of Study}

The study covered three areas, namely; Muko, Kamuganguzi Sub-counties (Kabale District) and Bubare Subcounty (Rubanda District) in southwestern Uganda (SWU) (Figure 2). These areas are highly populated, with scarce land resources, where SCI has the potential to contribute to sustainable livelihoods by intensifying potato crop production and conservation of the environment by communities in the region. They are popular potato growing areas in Uganda, which face a number of challenges because of the changing land tenure system, diminishing soil productivity, and unpredictable seasons. Highland areas where the study areas are located are susceptible to soil erosion, high population growth, land fragmentations, and overuse of land. Soil conservation practices were largely traditional, compromising mainly of crop-rotation, intercropping, and use of cover-crops, instead of terracing and use of trenches, which should be the commonest SCI interventions, owing to the mountainous topography of the area (Fungo et al., 2011:251, 255, 257). The study areas were chosen as they presented suitable considerations for the application of relevant bylaws and bylaw-centered policies to reinforce best practices in SCI. 


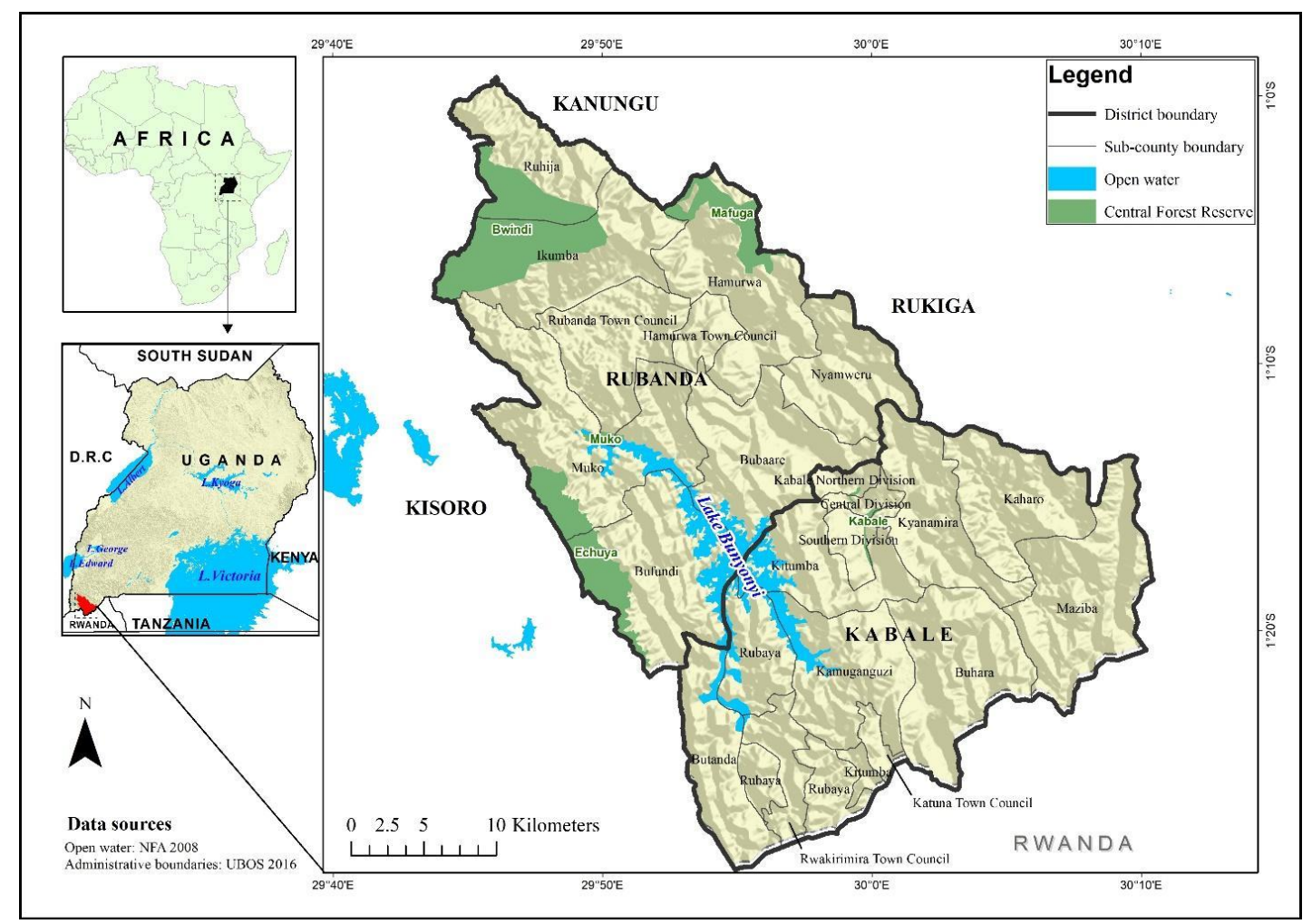

Figure 2. The map showing the study area in southwestern Uganda

\subsection{Study Design}

The study used descriptive case study design for in-depth understanding and correct explanations of effect relationships between variables of subjects in their natural setting (Sullivan-Bolyai and Bova, 2021). The study confirmed validity by comparing observations from more than one set of data since qualitative-based studies are most prone to bias. This study was able to understand and explain farmers' behaviour towards SCI

\subsection{Sampling Methods}

The study used a purposive sampling of potato farmers and reports on existing bylaws in selected study sites (Gentles, Charles, Ploeg, McKibbon, 2015). Experienced groups or associations and individual farmers represented the larger population of farmers in the region.

\subsubsection{Criteria for Selecting Participants}

The study identified specific characteristics of participants to show their relevance in providing accurate data. Harrison (2017) suggested that sources of data ought to be reliable for them to be included in the study. The sources of data were farmers, leaders of farmers' associations, and technical officials in the selected areas of study. The study provided 5 key characteristics of participants. This shows their relevance in informing the study so that consistent, most accurate, and reliable data could be obtained from them (Table 1).

Table 1. Criteria for recruiting participants

\begin{tabular}{cll}
\hline No. & Participants & Non-participants \\
\hline 1 & At least 2 years farming experience & Non-farmers or dis-engaged former farmers \\
2 & 18 to 75 years of age & Below 18 years of age \\
3 & Male or Female & Lacking right to own production land \\
4 & Farm owner & Lacking decision making influence on farming \\
5 & Resident of the areas studied & Living outside the areas of study \\
\hline
\end{tabular}

Source: Primary Data 


\subsection{Data Collection Instruments}

The data collection instruments used in this study were focus group discussions (FGDs) and key informant interviews.

\subsubsection{Focus Group Discussions}

The study conducted six focus group discussions (FGDs). Two FGDs were conducted in each of the sub-counties of Kamuganguzi (Kabale District), Bubare and Muko (Rubanda District) to minimize bias while gaining richer data from each of the stratum. Hennink, Kaiser, and Weber (2019) recommended at least two focused discussions for each of the stratum. This justifies decisions made by the study to conduct two focused discussions in three different locations (six FGDs). The FGDs consisted of 6-8 participants, and semi-structured, and open-ended questions. The discussions were simultaneous and in-depth discussions for homogenous groups of people, such as members of the farmers' associations. The semi-structured questions were informed by standardized tools for determining strong institutions and specific bylaws that supported SCI. Research has shown that four FGDs were appropriate sample for well-conducted group discussions. More than 4 group discussions (six in this case) provided much strong and reliable data to inform the study. Although four FGDs were sufficient to recognize patterns in the data, more group discussions strengthened comprehension by a researcher (Hennink et al., 2019). The use of FGDs saved time by meeting more than 6 participants in a single or few sessions rather than arrange 20 to 30 sessions for equal number of individual farmers. The use of FGD was most suited to the institutional-social aspect of the study. However, there was a tendency of dominance of specific participants despite efforts to spread participation among all of them. The dominant participants tended to dictate a specific data trends against the possibility of alternative views for overall consideration in the study. The use of collaborating data collection methods like key informant interviews (KIIs) improved validity of data that fell short of quality in FGDs due to impact of domineering participants on the general outcome of the study.

\subsubsection{Key Informant Interviews}

The study used key informant interviews (KIIs) to collect data from leaders of policy-led institutions, which consisted of representatives of farmers' associations and technical local government officials in the selected areas of the study. The total number of individual participants was 22 . There is a consensus among researchers that for descriptive case studies, 12-20 participants were adequate representation of the population size (Kim et al., 2017; Yin, 2014). Standardized tools or frameworks for assessing the strength of institutions and specific bylaws for achieving SCI informed the interview questions. The study selected participants to represent the study population because of their positions of responsibility, practical experiences, and expertise on potato crop production in the region. The KIIs sought expert opinions on matters pertaining to strength of institutional governance and impact on involvement of grassroots population or movements in supporting SCI. This facilitated the understanding of the influence of bylaws in institutional designs and policies in supporting SCI. The use of KIIs improved the quality data collected from FGDs, which often lost quality data because of limited participation by some discussants, or their misrepresentation by most active others.

\subsection{Analysis}

The study used existing frameworks for assessing strong institutions and specific bylaws (informal or informal) that effected farmers' behavior in order to support SCI. Burnard et al. (2008) explained that deduction analysis used existing structures to analyse data. In this study, frameworks for assessing effectiveness of institutions and existing bylaws guided analysis of data and generalisation of findings. Themes developed through repeated observations of response to specific thematic questions modified from standardised frameworks, such as the eight design principles of effective institutions and existing bylaws (informal and formal). Henceforth, deduction analysis led to holistic observation of unique and varying responses of participants (Kohlbacher, 2005). The themes are a collection of coded meanings, where each code represents a specific meaning (Sutton and Austin, 2015). In addition, the study assigned each specific meaning a label (a worded or qualitative meaning). Separate labels applied to positive and negative responses. Each label symbolised a specific pattern of behavior under each major pattern or theme. Minor behaviour responses were included for general understanding of different elements that featured in the study.

The study assigned numerical codes, such as $1,2,3,4 \ldots$ to each recognised pattern of behaviour at different levels, whether major or minor labels. The study allocated different codes to repeated responses, sequentially, to show how much emphasis-related ones (responses) had. The sequences of numerical responses for the respective labels were assigned a frequency number (number of times participants responded to a single case). This facilitated ranking of responses according to extent of emphasis in descending order. The ranking of labels for each research question, major labels or themes, minor labels or themes, and sub-minor labels or themes marked 
the end of descriptive qualitative analysis.

However, in this study, descriptive statistic's refined understanding of qualitative findings and clear comparison of findings from two data sets (FGDs and KIIs), whose respective findings were generalized as summary findings for the entire study. The admission of descriptive statistics, which is, otherwise, quantitative method, marked the use of mixed methods of research by converting frequencies of labels into percentage scores. This facilitates description of findings basing on the extent of percentage scores and comparing data for each of the research questions. The study considered only major labels for every major theme as summary findings since responses were numerous and extensive to be presented as such. Nevertheless, understanding of details of farmers' behaviors was vital part of the study because it informed research of major areas of policy interventions and specific areas of strengthening and appreciation or rewarding.

Further, for each of the research questions, summary tables show major themes and labels of specific codes under them in the first column, frequencies in the second column, and percentage scores in the third column, while the first upper row indicates headings for the respective column data details (categories). For coherent computation and tabulation of data, the study utilised Excel Spreadsheets to generate the descriptive statistics as integral part of findings.

\subsection{Ethical Consideration}

The research proposal was registered, peer-reviewed, and approved by the National Research and Ethics Committee at the Uganda National Council for Science and Technology (UNCST). The study sought consent approval of respondents before commencement of interviews.

\section{Findings of the Study}

\subsection{Description of Stakeholders in SCI of Potato Crop Production}

The stakeholders in SCI are government of Uganda and its agencies, Ministry of Agriculture Animal Industry and Fisheries (MAAIF), Local Councils (LCs), Uganda Police Force, extension workers, parish chiefs, district agricultural office, and national agricultural research organisation (NARO); community, farmer's association, Church, Uganda national seed producers' association); media; and international non-government organisations, international fertilizers development corporation (IFDC). Their roles are; decentrialisation of services, supervision of agricultural programmes, arbitration of cases, advisory and training services, implementation and monitoring of government programmes, technical support to farmers, innovation in viable seed varieties, participation in community-based services, pooling and efficient management of agricultural resources for sustainable livelihoods, acting as a platform for mobilization of communities for development, platform for creating awareness, collaboration and funding, as well as production of appropriate and quality fertilizers (Table 2).

Table 2. Shows description of stakeholders' in potato crop production

\begin{tabular}{lll}
\hline No. & Name & Role \\
\hline $\mathbf{1}$ & Central Government (Government of Uganda) & Decentralisation of services \\
1.1 & Ministry of Agriculture Animal Industry and Fisheries (MAAIF) & Supervision \\
1.2 & Local Councils (LCs) & Arbitration meetings \\
1.3 & Uganda Police Force & Enforcement \\
1.4 & Extension Workers & Advisory and training \\
1.5 & Parish Chiefs & Implementation \\
1.6 & District Agricultural Office & Technical support \\
1.7 & National Agricultural Research Organisation (NARO) & Quality seed varieties \\
$\mathbf{2}$ & Community & Community-help activities \\
$\mathbf{3}$ & Farmers' Association & Pooling and managing resources \\
$\mathbf{4}$ & Church (Catholic Church) & Mobilisation platform \\
$\mathbf{5}$ & Civil Society & Advocacy and campaigns \\
5.1 & Uganda National Seed Producers' Association (UNSPA) & Quality seed production \\
5.2 & Media & Awareness platform \\
$\mathbf{6}$ & International Non-government Organizations (INGOs) & Collaboration and funding \\
6.1 & International Fertilizers Development Corporation (IFDC) & Quality fertilizers \\
\hline
\end{tabular}

Source: Primary Data 


\subsection{The Relationship between Informal and Formal Bylaws in Supporting Sustainable Potato Crop Intensification in $S W U$}

The study found a greater influence of formal bylaws in supporting SCI than informal bylaws. The basis of this finding was the greater representation of documented formal bylaws. Overall, there was a greater concern for growing of eucalyptus and the need to discourage it (50 percent), followed by permission to graze (18 percent), and control damping (18 percent), while the widely represented formal bylaws had a comparatively lesser role in supporting SCI, with greater emphasis on improved and quality seed (22 percent). Most of the formal bylaws were below 10 percent score, such as ridge tillage, control of diseases, control grazing, digging channels, creating contours, selling in weight (kilograms), and fining outlaws. Nevertheless, both informal and formal bylaws were mutually reinforcing in supporting SCI. Hence, implementation of both bylaws categories contributed to responses by farmers towards SCI. In Figure 4, the study assessed institutional strength using Ostrom's eight design principles of effective institutions. The greatest score related to harmonized cost and benefits principle (52 percent and 22 percent for informal bylaws and formal bylaws, respectively) (Figure 4). Formal bylaws were stronger at setting clear boundaries between users and resources (18 percent), users having procedures for making own rules (11 percent), regular monitoring of resources and users (15 percent), issue sanctions (16 percent), conflict resolution (15 percent), and coordinated activities ( 3 percent) than informal bylaws. Hence, there was more compatibility with cost and benefits with informal than formal bylaws, although the latter proved most sustainable and comparably easier to influence behaviour of farmers to support SCI (Figure 3). Respondents from Kamuganguzi, Seed quality FGD (2018) confirmed the role of bylaws in supporting suitable potato crop intensification when they generally said:

“...we put up some of these bylaws so that we can get a better harvest because we said once you dig this trench when running water comes from up. Potatoes will be spoilt so once you put up your garden. You have to follow it up. So on such a bylaw, we as farmers have to implement it because you are the one liable to use it. The bylaws help us, and we love them very much because once you follow them the way we talked about them, even when you get a customer, and he comes into your seed potato store. He immediately appreciates before you even start bargaining because they will be looking well and are well protected, and so he will like them before you even talk to him."

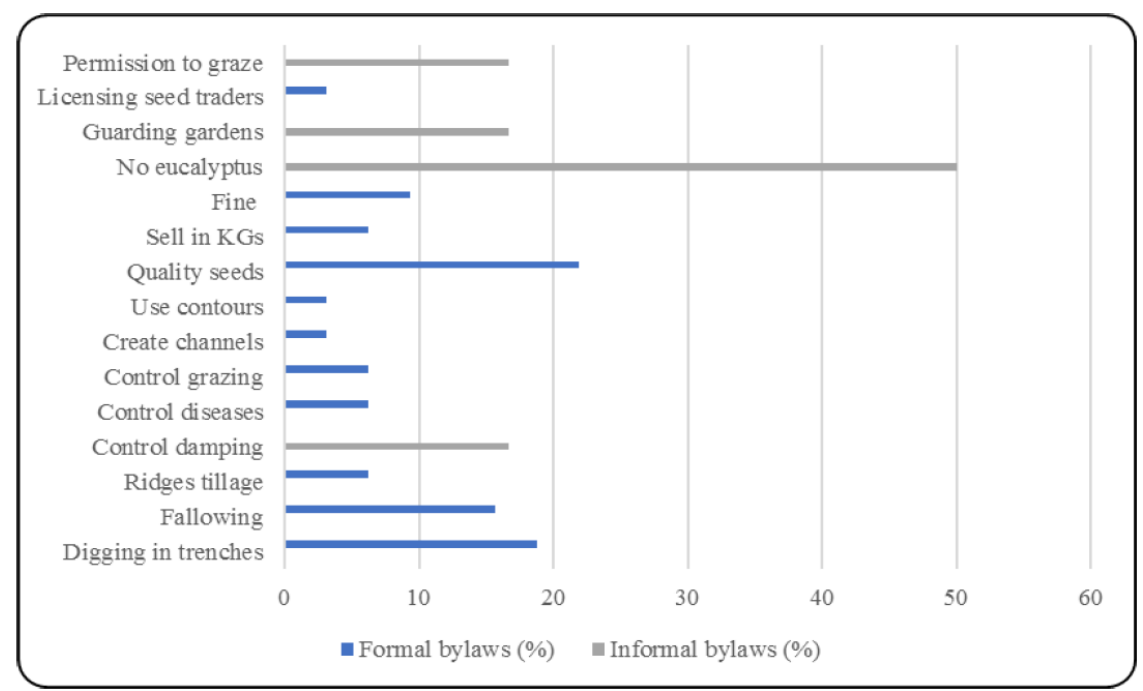

Figure 3. Shows relationship between informal and formal bylaws in supporting SCI

Source: Primary Data 


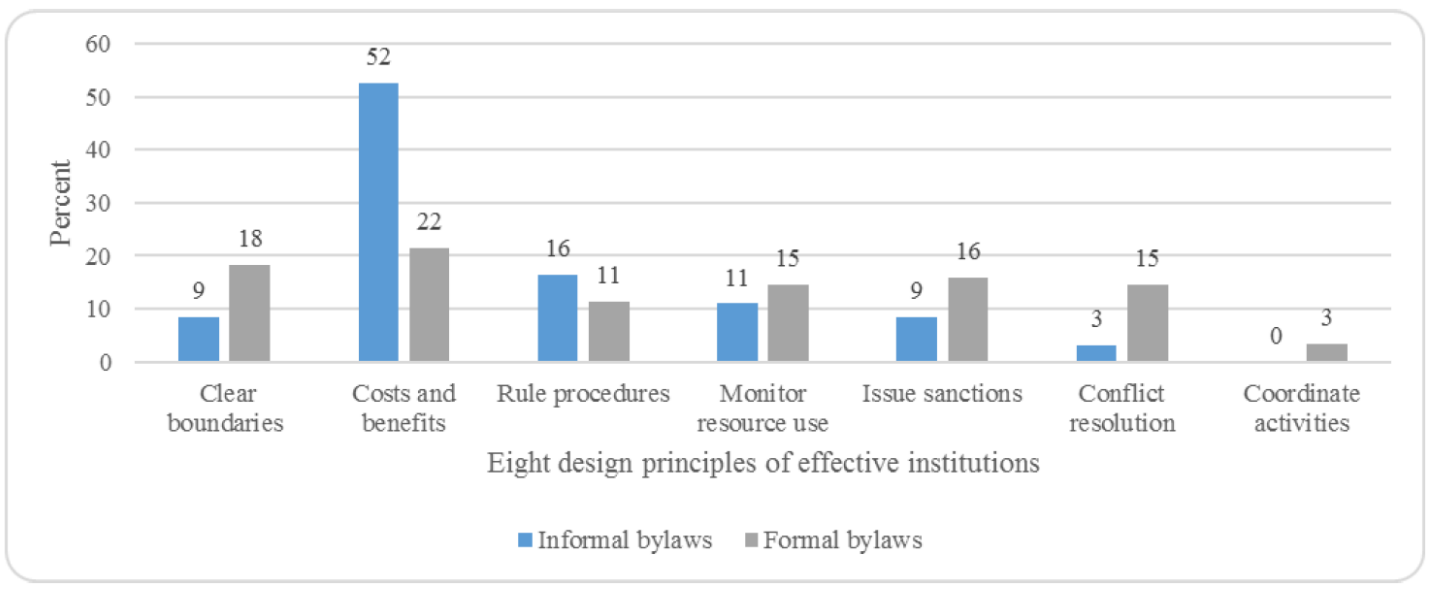

Figure 4. Shows assessment of institutions using the eight design principles of effectiveness

Source: Primary Data

\subsection{What is the Role of Individual and Institutional Frameworks in Supporting Sustainable Potato Crop Intensification?}

The role of institutions in supporting SCI in potato producing areas in SWU was most predominant in comparison of individual farmers (Figure 5). The major benefits for operating as institution were the collective strategy for the market (26 percent), which proved most challenging to individual farmers who opted to use small network of family members to market their produce. Institutional operations were involved in bargaining, buying produce, storing it until prices were favourable, and better prices. The individual farmers were renowned for believing in faster benefits by operating outside farming institutions, like farmers' associations (12 percent). Institutional capacities were still low on many aspects of sector development (less than 10 percent), such as mobilization of resources, record keeping, saving, conflict resolution, policy development and implementation, quality control, licensing seed producers, and administration. While working within the framework was more sustainable in terms of yielding socioeconomic benefits, high-quality potato production, and natural resources use than individualism (using individual knowledge and value system) to support SCI in SWU, highest institutional score of 26 percent was too small to attract individual farmers to join and benefit from market potential. Farmers incurred greater costs using formal bylaws to support SCI. Bubare Innovation Platform official (March 2018) observed:

"IFDC is doing training farmers, demonstration gardens, giving fertilizers and seed spraying pumps even has put up some storage facilities. Then we have NARO, which is also doing training. They move around certifying people like seed producers."

"The committee for quality control, once they go to supervise, and they find that your garden is not looking well, on the seed column we will note. We make sure that these fields they want to plant in potatoes fields fit to grow potatoes for seed. How long have they taken without being used for potato growing or are they in the low land where floods or running water will be collecting. And this field, if our member is going to cultivate it, is he/she following those things or bylaws that they are telling us? ... the seed he is going to plant; we have to investigate whether he got it from a known seed producer or a research firm." 


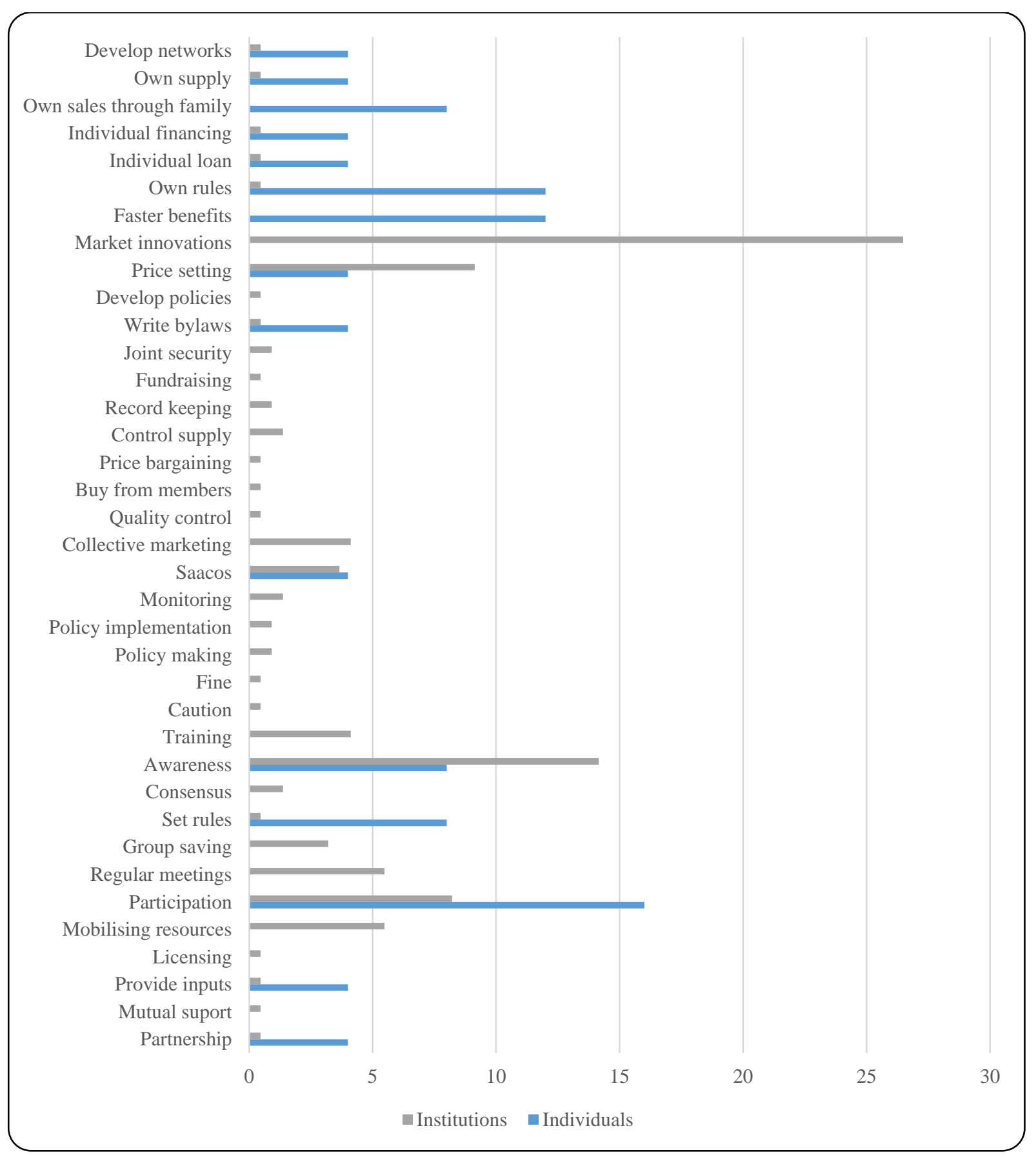

Figure 5. Shows individual and institutional roles in supporting SCI

Source: Primary Data

\subsection{What is the Effect of Informal and Formal Bylaws on Sustainable Potato Crop Intensification in SWU?}

The study found more emphasis on market access, regardless of the nature of produce output (35 percent), whether they are market worthy or not. The variables for SCI were least considered such as soil conservation in the use of fertilizers, equipment, packaging, transport, and price instability, because farmers do not find adequate motivation to commit to potato production, all which have scores below 10 percent, yet returns from the market are not impressive (35 percent). Hence, the bylaws have not been able to strengthen the response towards SCI (Figure 6). 


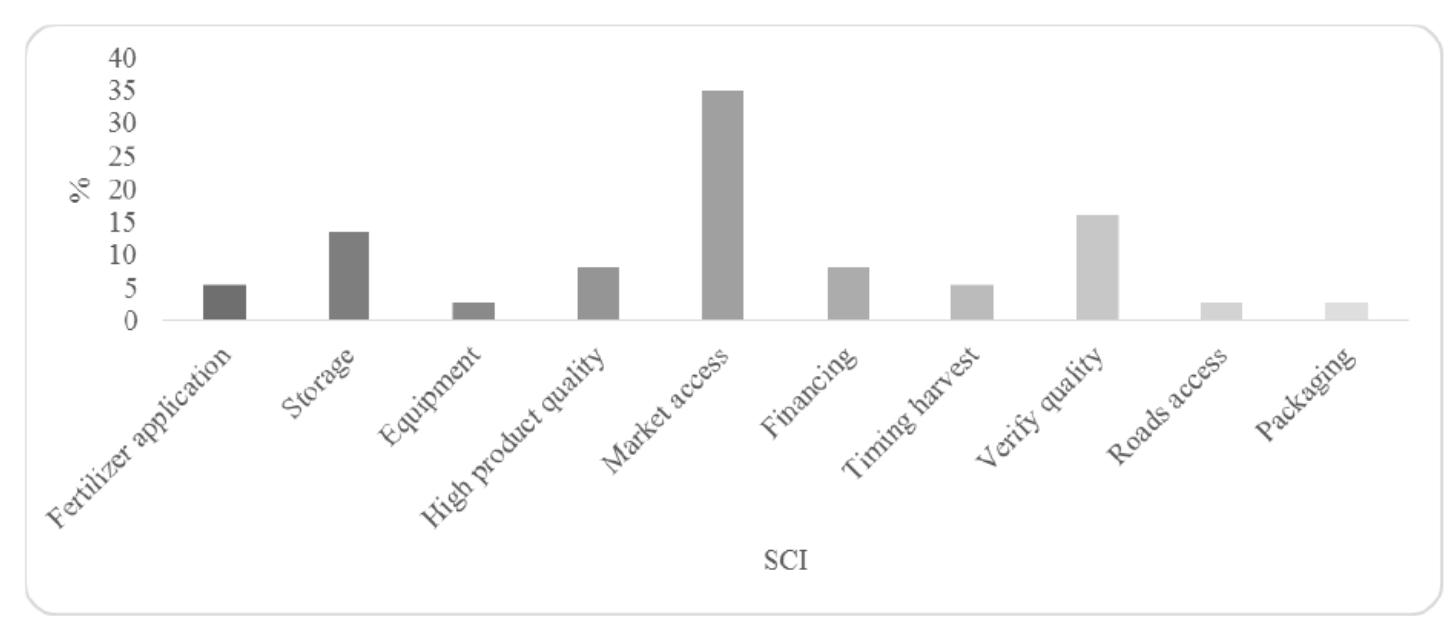

Figure 6. Shows effect of informal and formal bylaws on SCI

Source: Primary Data

\section{Discussion}

In this section, the study reflects on the results in relation to the literature review, as well as the theoretical and conceptual frameworks to confirm areas of agreement and disagreement and implications to the study. The discussion follows the order of presentations in the previous section (4.1), based on the key findings for each of the objectives provided to draw implications to scholarship on SCI in the potato cropping system. In the findings, the scores show a number of mentions and percentages to facilitate the description of the phenomena.

The study found expressed greater influence of informal bylaws with respect to no eucalyptus (50 percent), seeking permission to graze (18 percent), and control dumping (18 percent). Formal bylaws were widespread but less influential in boosting response towards SCI, with great focus on seed quality, which could not act in isolation without the functioning of other formal bylaws, which mostly were under 10 percent score. Costs and benefits were more harmonized under the influence of informal bylaws than formal bylaws ( 52 percent and 22 percent, respectively). However, formal bylaws showed greater strength at setting clear boundaries between users and resources than informal bylaws (18 percent. Formal bylaws were stronger at setting clear boundaries between users and resources (18 percent), users having procedures for making own rules (11 percent), regular monitoring of resources and users (15 percent), issue sanctions (16 percent), conflict resolution (15 percent), and coordinated activities ( 3 percent) than informal bylaws. The findings show separate roles of informal and formal bylaws in supporting the intensification of potato crop production, even when formal bylaws evolved from informal bylaws. That is from unwritten to written bylaws. This explanation originates from the new institutionalism theory by North (1990), which affirms that socialization of values to become social norms and bylaws to guide group behaviour in handling conflicts in using the limited natural resources to sustain livelihoods. The importance of bylaws, thus, remains central in sustainable potato crop intensification in SWU. However, they must be known to people they target for them to be meaningful, and be communicated regularly until expected behaviour takes root in the lives of farmers for them to passionately intensify potato crop production in the region.

The study finds a greater role of institutions than individual farmers in supporting sustainable potato crop intensification in SWU. The farmers enjoyed greater prospects operating within institutional framework than as individuals, because of the greater levels of efficiency associated with them, especially in terms of accessing better markets compared to individual farmers who sought faster benefits, instead (13 percent). Both demonstrated no concern for the sustainability of production and the environment. Research has shown SCI a very relevant way of transforming the socio-economic lives of people amidst escalating food security and livelihood challenges in the region. The study shows limited policy influence on SCI and negligible influence of bylaws on policy development within institutions, which is a basis of their strength in delivering their mandate. The institutions demonstrate gaps between their role and action in supporting the intensification of potato crop production. This explains why individual farmers re reluctant to join farmers' associations. This contrasts Yami and Van Asten works in 2009; 2017; and 2018 in support of institutionalising crop production as a way to intensify it. Particularly Yami et al. (2009), whose work focuses on sustainable management of the common-pool 
resource in the Tigray region in Ethiopia, acknowledge the role of local knowledge systems in the management of common-pool resources. These studies confirm that, for institutions to be effective, they must organically have evolved and incorporated grass-root bylaws as a basis of their regulatory frameworks in guiding and influencing stakeholders towards SCI. As opposed to the top-down approach, the effective roles of institutions are such that the bottom-up approach to decision making supersedes top-down other for sustainability good, especially when actors were well-coordinated to focus on SCI in their parallel functions towards the same purpose (SCI). The failure and weaknesses of institutions potentially drive away resourceful members, because of the lost trust and confidence that results from the poor coordination and limited progress of farmers' associations.

The effects of bylaws (informal and formal bylaws) and bylaw-based policies on SCI were limited in both scope and intensity, which undermine efforts towards food security, and socioeconomic transformation SWU. Unfortunately, the trend influenced SCI the same way such that direction farmers' perception and behaviour targets financial returns ( 35 percent) through market access rather than improved and quality seed, soil and water conservation, and environmental sustainability, which maintains and improves it. While SCI shows greater seed quality verification exercise, in practice, there is little that is done to guarantee seed quality. Even access to market proved below the expected one. The explanation for the low SCI is the weak bylaws and institutional framework for implementing them, which as Ostrom put it, they deserved better governance to be effective. Ostrom suggested eight design principles of developing strong institutions that can best support SCI, such as defining clear boundaries of the shared resource, negotiating for a system that reward members, making rules and decisions by consensus, monitoring vulnerability and overexploitation of resources, issuing sanctions for members, resolving conflict in just ways to the group, recognising minimum rights of members, and coordinating groups of the larger social systems (Cox, Arnold, Villamayor-Tomas, 2010; Sumane et al., 2017). This provides an insight into how effective to manage farmers' associations to best implements bylaws that are relevant to sustainable potato crop intensification in SWU. Walukano et al., (2016) made similar assertions related to seed quality that investing in improved and quality seeds more than quadrupled the yield of potatoes and was very rewarding. In other words, addressing the problem of seed quality in the potato cropping system resolved more than half the challenges of low yields. The other factor that explained the increased adoption of bylaws on seed quality was the practice of motivating farmers to adopt commercial farming.

The design of the study used myriad of arguments and methods to support the underlying qualitative foundation of it. Furthermore, the diverse arguments, theories, and methods aimed at addressing issues of rigor, by strengthening both internal and external validity of the study. Future studies may need conduct survey-based studies on the same topic to qualify the qualitative-based approach of this study

\section{Conclusions}

The bylaws (informal and formal) were rudimentary and scattered, appearing as best practices rather than a reference manual, and most of them had evolved away from informal (unwritten) to formal (written) phase, with the formal and predominant in influencing farmers' actions to intensify potato crop production. Despite their unique characteristics, they both supported the intensification of potato crop production in SWU.

The role of the institutional framework for implementing bylaws was most influential, though the individual-based value system came quite close in influencing SCI. Both fell under the category of the private sector, though the institutional ethic was most relevant in sustainable potato crop intensification because it covered both breadth and intensity in supporting SCI. Efficacy was the greatest challenge due to the parallel functioning of actors and weak coordination of the overall activities towards sustainable potato crop intensification in SWU.

The effects of bylaws on SCI were both direct (on primary makers of the bylaws) and indirect (on individuals and institutions who adopt them) to guide response towards SCI. The effect of informal and formal bylaws on sustainable crop intensification was limited, despite the noble role they played in supporting SCI, because of the limited focus soil and water conservation, quality of seed potato, and environmental sustainability in favour of consumption The emphasis was on improved and quality seed and storage facilities, which too failed to guarantee expected standards towards stronger SCI in SWU.

\section{Recommendations}

1. There is need to strength bylaws on soil and water conservation, improved and quality, seed and environmental sustainability to support SCI, which provide the basis of greater markets and sustainable livelihoods. 
2. There is a need for a proper and distinct manual on bylaws for standardization, regionalization, and nationalization purposes to best influence farmers towards SCI.

3. There is a need to develop strong institutional, management structures, and coordination structures among the various actors that address institutional and management or implementation challenges of bylaws to support SCI.

4. There is a need for the most influential role of government and development partners in the intensification of potato crop production in SWU so that the relentless efforts of farmers' groups can be strengthened, and the confidence of individual farmers to join farmers' associations be improved.

\section{Funding}

The research was supported by IITA Uganda under the Policy Action for Sustainable Intensification of Ugandan Cropping systems (PASIC) project funded by the Embassy of the Kingdom of The Netherlands in Uganda and the Regional Universities Forum for Capacity Building in Agriculture (RUFORUM) [RU/2016 /Carnegie/DRG/005].

\section{References}

Boserup, E. (1965). Conditions of agricultural growth. Chicago: Aldine Publications.

Brookfield, H. (2001). Intensification, and Alternative Approaches to Agricultural Change. Asia Pac. View, 42(2e3), 181-192. https://doi.org/10.1111/1467-8373.00143

Burnard, P., Gill, P., Stewart, K., Treasure, E., \& Chadwick, B. (2008). Analysing and representing qualitative data. British Dental Journal, 204, 429-432. https://doi.org/10.1038/sj.bdj.2008.292

Cox, M., Arnold, G., \& Villamayor-Tomas, S. (2010). A review of design principles for community-based natural resource management. Ecology and Society, 15(4), 38. https://doi.org/10.5751/ES-03704-150438

Djurfeldt, G. (2005). The African Food Crisis: Lessons from the Asian Green Revolution. https://doi.org/10.1079/9780851999982.0000

FAO, IFAD, UNICEF, WFP, \& WHO. (2021). The State of Food Security and Nutrition in the World 2021.

Fungo, B., Tenywa, M., Majaliwa, J., Kuule, M., \& Kamugisha, R. (2011). Use of soil conservation practices in the Southwestern highlands of Uganda. Journal of Soil Science and Environmental Management, 3(9), 250-259. Retrieved from http://www.academicjournals.org/JSSEM

Garnett, T., Appleby, M. C., Balmford, A., Bateman, I., Benton, T., ... Godfray, C. (2013). Sustainable Intensification in Agriculture: Premises and Policies. Science, 341, 33-4. https://doi.org/10.1126/science.1234485

Gentles, S. J., Charles, C., Ploeg, J., \& McKibbon, K. A. (2015). Sampling in qualitative research: Insights from an overview of the methods literature. The Qualitative Report, 20(11), 1772-1789. https://doi.org/10.46743/2160-3715/2015.2373

Harrison, H., Birks, M., Franklin, R., \& Mills, J. (2017). Case study research: foundations and methodological orientations. Forum Qualitative Sozialforschung / Forum: Qualitative Social Research, 18(1). https://doi.org/10.17169/fqs-18.1.2655

Helmke, G., \& Levitsky, S. (2004). Informal institutions and comparative politics: a research agenda. Perspect. Polit., 2(04), 725-740. https://doi.org/10.1017/S1537592704040472

Hennink, M., Kaiser, B. N., \& Weber, M. B. (2019). What Influences Saturation?. Estimating Sample Sizes in Focus Group Research, 29(10). https://doi.org/10.1177/1049732318821692

Kim, H., Sefcik, J. S., \& Bradway, C. (2017). Characteristics of qualitative descriptive studies: A systematic review. Research in Nursing \& Health, 40(1), 23-42. https://doi.org/10.1002/nur.21768

Kohlbacher, F. (2005). The use of qualitative content analysis in case study research. Forum Qualitative Sozialforschung / Forum: Qualitative Social Research, 7(1), 21. Retrieved from http://nbn-resolving.de/urn:nbn:de:0114-fqs0601211

Ministry of Agriculture, Animal Industry, and Fisheries. (2013). National Agriculture Policy. Kampala: MAAIF.

NAADS. (2020). Irish potatoes production. Retrieved from https://naads.or.ug/irish-potatoes-production

North, D. C. (1990). Institutions, institutional change, and economic performance. Cambridge University Press, Cambridge. https://doi.org/10.1017/CBO9780511808678 
Ostrom, E. (1990). Governing the commons: the evolution of institutions for collective action. Cambridge University Press, UK. https://doi.org/10.1017/CBO9780511807763

Otsuka, K., \& Place, F. (2014). Evolutionary changes in land tenure and agricultural intensification in Sub-Saharan Africa. United Nation University: Working Paper. https://doi.org/10.35188/UNU-WIDER/2014/772-1

Pretty, J., Toulmin, C., \& Williams, S. (2011). Sustainable intensification in African agriculture. International Journal of Agricultural Sustainability, 9(1), 5-24. https://doi.org/10.3763/ijas.2010.0583

Sanginga, P. C., Abenakyo, A. R., Martin, M. A., \& Muzira, R. (2009). Tracking outcomes of participatory policy learning Kamugisha and action research: Methodological issues and empirical evidence from participatory bylaw reforms in Uganda. Society \& Natural Resources, 23(8), 711-725. https://doi.org/10.1080/08941920802192207

Schut, M., Astenc, P., Okaford, C., Hicintukae, C., Mapatanof, S., ... Vanlauweh, B. (2016). Sustainable intensification of agricultural systems in the Central African Highlands: The need for institutional innovation. Agric. Syst., 145, 165-176. https://doi.org/10.1016/j.agsy.2016.03.005

Strehlenert, H., Richter-Sundberg, L., Nyström, M. E., \& Hasson, H. (2015). Evidence-informed policy formulation and implementation: a comparative case study of two national policies for improving health and social care in Sweden. Implementation Sci, 10, 169. https://doi.org/10.1186/s13012-015-0359-1

Sullivan-Bolyai, S. L., \& Bova, C. A. (2021). Qualitative description: a "how-to" guide. University of Massachusetts Medical School Publications. https://doi.org/10.13028/8vwe-xc61

Sumane, S., Kundaa, I., Knickelb, K., Straussc, A., Tisenkopfsa, T., ... Ashkenazyf, A. (2017). Local and farmers' knowledge matters! How integrating informal and formal knowledge enhances sustainable and resilient agriculture. Journal of Rural Studies, 59, 232-241. https://doi.org/10.1016/j.jrurstud.2017.01.020

Sutton, J., \& Austin, Z. (2015). Qualitative Research: Data Collection, Analysis, and Management. CJHP, 68(3), 226-230. https://doi.org/10.4212/cjhp.v68i3.1456

United Nations Industrial Development Organization (UNIDO). (2020). Industrialization as a driver to sustained growth. Vienna: UNIDO, 2020, 8.33.34. Retrieved from https://www.unido.org/sites/default/files/files/2020-04/UNIDO_Industrialization_Book_web4.pdf

Vanlauwe, B., Coyne1, D., Gockowski, J., Hauser, S., Huising, J., ... Van Asten, P. (2014). Sustainable intensification and the African smallholder farmer. Current Opinion in Environmental Sustainability, 8, 15-22. https://doi.org/10.1016/j.cosust.2014.06.001

Walukano, W., Nanfumba, D., Arinaitwe, A., Basalirwa, D., Asiimwe, R., \& Pali, P. (2016). Yield gap analyses to inform policy on crop intensification pathways in Uganda. A paper presented at the Tropentag 2016, Vienna, Austria.

Xie, H., Huang, Y., Chen, Q., Zhang, Y., \& Wu, Q. (2019). Prospects for Agricultural Sustainable Intensification: A Review of Research. Land, 8, 157. https://doi.org/10.3390/land8110157

Yami, M., \& Asten, P. (2018). The relevance of informal institutions for achieving sustainable crop intensification in Uganda. Springer Science + Business Media B.V., part of Springer Nature and International Society for Plant Pathology. https://doi.org/10.1007/s12571-017-0754-3

Yami, M., \& Asten, P. (2017). Policy support for sustainable crop intensification in Eastern Africa. Journal of Rural Studies, 55. 216-226. https://doi.org/10.1016/j.jrurstud.2017.08.012

Yami, M., Vogl, C., \& Hauser, M. (2009). Comparing the effectiveness of informal and formal institutions in sustainable common pool resources, management in Sub-Saharan Africa. Conservation and Society, 7(3), 153-164. https://doi.org/10.4103/0972-4923.64731

Yami, M., Mekuria, W., \& Hauser, M. (2012). The effectiveness of village bylaws in sustainable management of communitymanaged exclosures in Northern Ethiopia. Sustain Sciences, 8, 73-86. https://doi.org/10.1007/s11625-012-0176-2

\section{Copyrights}

Copyright for this article is retained by the author(s), with first publication rights granted to the journal.

This is an open-access article distributed under the terms and conditions of the Creative Commons Attribution license (http://creativecommons.org/licenses/by/3.0/). 